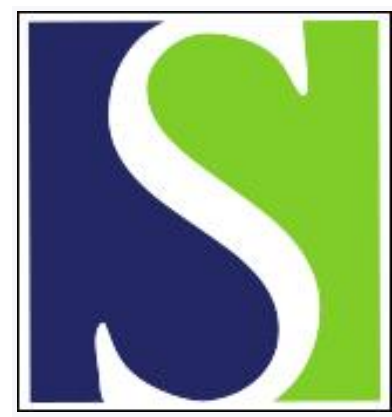

Scand J Work Environ Health 2016;42(5):405-412

https://doi.org/10.5271/sjweh.3574

Published online: 01 Jun 2016, Issue date: 01 Sep 2016

Pre-retirement physical working conditions and changes in physical health functioning during retirement transition process

by Mänty M, Kouvonen A, Lallukka T, Lahti J, Lahelma E, Rahkonen O

It is not known if physical working conditions before retirement affect changes in physical functioning during the retirement process. This current study showed that retirees with higher exposure to adverse physical working conditions before retirement had lower pre- and post-retirement physical functioning despite improvements in their functioning during the retirement transition process.

Affiliation: Department of Public Health, University of Helsinki, P.O. Box 20, FIN-00014, Finland. minna.manty@helsinki.fi

Refers to the following texts of the Journal: $2011 ; 37(3): 213-218$ 2016;42(1):71-79

Key terms: ageing; ageing employee; change in physical health functioning; computer work; environmental hazard; follow-up; older employee; physical health; physical health functioning; physical working condition; physical workload; pre-retirement; retirement; retirement transition process; SF-36

This article in PubMed: www.ncbi.nlm.nih.gov/pubmed/27249309

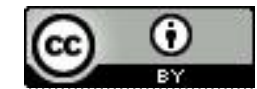




\title{
Pre-retirement physical working conditions and changes in physical health functioning during retirement transition process
}

\author{
by Minna Mänty, PhD, ${ }^{1}$ Anne Kouvonen, PhD, ${ }^{2,3,4}$ Tea Lallukka, PhD, ${ }^{1}$ Jouni Lahti, PhD, ${ }^{1}$ Eero Lahelma, PhD, ${ }^{1}$ \\ Ossi Rahkonen, $P h D^{1}$
}

\begin{abstract}
Mänty M, Kouvonen A, Lallukka T, Lahti J, Lahelma E, Rahkonen 0. Pre-retirement physical working conditions and changes in physical health functioning during retirement transition process. Scand J Work Environ Health. 2016;42(5):405-412. doi:10.5271/sjweh.3574
\end{abstract}

Objectives The aim of this study was to examine the association between pre-retirement physical working conditions and changes in physical health functioning during the retirement transition process.

Methods Follow-up survey data were collected among ageing employees of the City of Helsinki, Finland, at three time points: wave 1 (2000-2002), wave 2 (2007) and wave 3 (2012). We focused on those who retired full time due to old age between waves 1 and $3(\mathrm{~N}=1658)$. Exposure to physical workload, occupational environmental hazards, and computer work were divided into quartiles and used as measures of pre-retirement physical working conditions. Physical health functioning was measured by the physical component summary (PCS) of the Short-Form 36 questionnaire. Repeated-measures analysis was used to study the associations.

Results Higher pre-retirement exposure to physical workload and environmental hazards was associated with lower physical health functioning before and after retirement. The differences in functioning narrowed somewhat during the retirement transition process, as physical health functioning in the higher exposure groups improved significantly compared to lower exposure groups. In addition, both high and low exposure to computer work were associated with lower functioning before retirement. However, functioning among those in the lowest exposure group improved during the follow-up whereas in all other exposure groups it declined slightly. This resulted into significantly lower post-retirement functioning among those in the highest as compared to the lower exposure groups.

Conclusions Retirees with higher exposure to adverse physical working conditions before retirement had lower pre- and post-retirement physical health functioning despite improvements in their functioning during the retirement transition process.

Key terms ageing; ageing employee; follow-up; older employee; SF-36; physical workload; environmental hazard; computer work.

Good physical functioning is vital for everyday life. Loss of physical functioning, such as difficulties in walking, is an early marker of declining health, and threatens the individual's independence and quality of life $(1,2)$. Many clinical and epidemiological studies have identified multiple determinants of functional decline, such as various chronic diseases, and sociodemographic and lifestyle factors $(3,4)$.

Adverse physical working conditions are potentially important risk factors for declining physical health par- ticularly later in life. For example, previous studies have suggested that physically demanding working conditions, such as repetitive monotonous work or lifting (5-8), are associated with poorer physical health functioning among midlife and older employees. Other studies have further indicated that exposure to high physical workload is associated with lower physical health functioning also after retirement $(7,9)$. In addition, physical inactivity across adulthood has cumulative adverse effects on physical health functioning in midlife and old age $(10,11)$, how-

1 Department of Public Health, University of Helsinki, Helsinki, Finland.

2 Department of Social Research, University of Helsinki, Helsinki, Finland.

3 University of Social Sciences and Humanities, Faculty in Wroclaw, Wroclaw, Poland.

4 UKCRC Centre of Excellence for Public Health (Northern Ireland), Queen's University Belfast, Belfast, UK.

5 Finnish Institute of Occupational Health, Helsinki, Finland.

Correspondence to: Minna Mänty, Department of Public Health, University of Helsinki, P.O. Box 20, FIN-00014, Finland. [E-mail: minna. manty@helsinki.fi] 
ever, prospective evidence on the effects of sedentary computer work on physical health functioning is lacking. Furthermore, various environmental hazards at work, such as high exposure to occupational noise, hazardous substances or dust, may also threaten employees' health in the long term (12-15), but it is not known whether exposure to occupational environmental hazards is reflected in physical health functioning.

Retirement - one of the major life transitions - is also likely to have important consequences for health $(16,17)$. However, current empirical evidence on the effects of retirement on physical health is scarce and inconsistent, with some previous studies indicating that physical health functioning may improve (18), deteriorate (19), or remain unaffected (20) after retirement. Furthermore, previous studies on physical health functioning have focused on post-retirement changes only and studies focusing on changes during the retirement transition process, that is, from pre- to post-retirement, are rare $(21,22)$. And it is not known if physical working conditions before retirement affect changes in physical health functioning during the retirement process.

The aim of this study was to examine the associations between physical working conditions before transition to old-age retirement and changes in physical health functioning during the retirement transition process, that is, from pre- to post-retirement.

\section{Methods}

\section{Participants and ascertainment of old-age retirement}

This study is part of the Helsinki Health Study, which examines the health and well-being among the ageing employees of the City of Helsinki, Finland. Wave 1 data were collected by postal surveys in 2000, 2001 and 2002 among employees reaching 40, 45, 50, 55 or 60 years of age in each year $(\mathrm{N}=8960)$ (23). The follow-up surveys were conducted in 2007 (wave 2) and 2012 (wave 3). Of the wave 1 participants, $83 \%(\mathrm{~N}=7332)$ responded also to the wave 2 survey, and $79 \%(\mathrm{~N}=6814)$ to the Wave 3 survey. Data on retirement were obtained from the national registers of the Finnish Centre for Pensions, providing complete information on all retirement events. These data were linked to the survey data using unique personal identification numbers assigned to each Finnish resident. The data linkage was done for those wave 1 respondents who gave their written consent for such linkage $(74 \%, N=6605)$. According to the non-response analysis, the wave 1 and follow-up data, as well as the data linkage consenter population satisfactorily represent the target population $(23,24)$.

For the purposes of this study, we focused on those who retired full-time due to old age between waves 1 and 2, that is period $1(\mathrm{~N}=1133)$, and between waves 2 and 3 , that is period $2(\mathrm{~N}=1030)$. We did not include those with history of part- or full-time disability retirement before or during the study. Period 1 and 2 retirees were merged in the analysis $(\mathrm{N}=2163)$. Of these, 1844 participated in the pre-retirement (phase 1 for period 1 retirees and phase 2 for period 2 retirees) as well as post-retirement (phase 2 for period 1 retirees and phase 3 for period 2 retirees) surveys. Furthermore, respondents with missing information on physical health functioning before or after retirement $(\mathrm{N}=133)$ or on the physical working conditions before retirement $(\mathrm{N}=53)$ were excluded. This yielded 1658 participants.

The ethics committees of the Department of Public Health, University of Helsinki, and the health authorities of the City of Helsinki, Finland, approved the Helsinki Health Study.

\section{Measurement of physical workload}

Physical working conditions were measured at each time point using an 18-item inventory (25). The participants were asked whether they were exposed to each condition and to what extent it bothered them with the response alternatives: "does not exist", "exits but does not bother", "exists and somewhat bothers", and "exists and bothers a lot". Following the procedures used also in our previous work $(15,26)$, three factors were identified by factor analysis: physical workload, computer work and occupational environmental hazards. Six items loaded on the physical workload factor: uncomfortable postures, repetitive trunk rotation, repetitive movements, heavy physical work, standing and walking (Cronbach $\alpha=0.81$ for period 1 retirees and Cronbach $\alpha=0.84$ for period 2 retirees). Three items loaded on the computer work: working with a computer display terminal, using a computer mouse, and doing sedentary work (Cronbach $\alpha=0.77$ for period 1 retirees and Cronbach $\alpha=0.84$ for period 2 retirees). The third factor, that is, occupational environmental hazards, comprised exposures to dirt and dust, dampness and wetness, noise, solvents or other irritating substances, and problems with lighting or temperature (Cronbach $\alpha=0.79$ for period 1 retirees and Cronbach $\alpha=0.80$ for period 2 retirees). In each of the factors, a high score indicates high exposure and participants were stratified into quartiles based on their factor scores: 1 (low exposure) - 4 (high exposure).

\section{Measurement of physical health functioning}

Physical health functioning was measured by the physical component summary (PCS) of the Short-Form 36 (SF-36) health questionnaire (27) at each of the three waves. The SF-36 includes 36 items and comprises eight 
subscales: physical functioning, role limitations due to physical problems, bodily pain, general health perceptions, mental health, role limitations due to emotional problems, social functioning and vitality. These eight subscales were compressed by means of factor analysis into two component summaries: the physical and mental component summaries (PCS and MCS). Each of these subscales positively or negatively contribute to PCS and MCS. The first four subscales mentioned are referred to as physical subscales. For the purposes of this study, we included the PCS scores at each time point. The PCS is a continuous scale, ranging from $0-100$, with a mean of 50 [standard deviation (SD) 10)] in the general US population (27). High scores indicate good physical health functioning. The SF-36 has a good construct validity as well as high internal consistency and testretest reliability (27).

\section{Covariates}

Age, gender, and education were obtained from the phase before retirement. Other variables were measured before and after retirement and were used as timevariant. Education was divided into three levels: (i) higher education, ie, university degree; (ii) intermediate education, ie, matriculation or college examination and (iii) basic education, ie, secondary or vocational school. Body mass index was calculated using self-reported weight in kilograms divided by height in meters squared, and classified into non-obese $\left(\leq 30 \mathrm{~kg} / \mathrm{m}^{2}\right)$ and obese $\left(>30 \mathrm{~kg} / \mathrm{m}^{2}\right)$. Leisure-time physical activity was categorized into two levels: inactive $=\leq 14$ metabolic equivalent (MET) hours/week and active $=>14$ MET hours/ week (eg, brisk walking for 30 minutes, 5 days/week = 15 MET hours/week). The main analysis used a list of self-reported medically confirmed chronic diseases that are likely to affect physical functioning (osteoporosis, osteoarthritis, rheumatoid arthritis, angina pectoris, heart attack, cerebral hemorrhage, intermittent claudication, asthma, depression, other mental illness, diabetes and cancer). For descriptive purposes the following categories were used: 0,1 or $\geq 2$ diseases.

\section{Statistical methods}

Study population characteristics are reported as percentages and mean values of SF-36 physical health functioning score (PCS) before retirement with $95 \%$ confidence intervals $(95 \% \mathrm{CI})$. The effect of pre-retirement physical working conditions on physical health functioning during retirement transition process was analyzed in two steps: First, the adjusted cross-sectional differences in PCS score before and after retirement were calculated by pre-retirement physical working conditions using linear regression analysis. In these analyses, the covariates were derived from the same time-point as PCS. To be able to evaluate, whether the observed group differences before retirement remain also after retirement, when the occupational exposures are removed, we report the mean differences separately for both, before and after retirement time-points. Second, adjusted group specific changes of PCS score during the retirement transition process were calculated with repeated measures analysis using PROC MIXED procedure in SAS. This group specific approach allows to evaluate if the change in physical health functioning differs between the exposure groups during the retirement transition process. In these longitudinal analyses, the covariates were used as timevariant. All analyses were adjusted for age and gender. Further adjustments were done for obesity, chronic diseases and physical activity (model 2 ), and for education (model 3). In model 4, all three physical working condition factors were simultaneously adjusted for each other. The results are reported as regression coefficients $(\beta)$ and their standard errors (SE). Men and women were pooled in the analyses as gender interactions were statistically non-significant $(\mathrm{P}>0.05)$. The SAS 9.4 statistical package was used for all analyses (SAS institute Inc, Cary, NC, USA).

\section{Results}

The mean age of the participants at baseline was 59.3 (SD 2.6) years. Physical health functioning before retirement was lower among women than men and those who had one or more chronic diseases. In addition, obesity, and low leisure-time physical activity and low education were associated with poorer physical health functioning (table 1.)

Higher exposure to physical workload and occupational environmental hazards before retirement were associated with lower physical health functioning before and after retirement (table 1, table 2). These differences narrowed slightly during the retirement transition process as physical health functioning in the two highest exposure categories (quartiles 3 and 4 ) improved significantly $(\mathrm{P}<0.05)$ compared to the opposite declining trend in the two lowest exposure categories (quartiles 1 and 2) (table 3). For example, those in the highest physical workload category had $5.3(\mathrm{P}<0.001)$ points lower score before retirement as compared to those in the lowest quartile (table 2). Although functioning among those in the highest exposure quartile improved significantly during the follow-up compared to those in the lowest quartile $(+1.5$ versus $-0.8, \mathrm{P}<0.001$, table 3 ), those in the highest exposure category had still 3.0 $(\mathrm{P}<0.001)$ points lower physical health functioning score also after retirement (table 2). Further adjustments for 
Table 1. Unadjusted percentage of participants and Physical Component Summary (SF-36) mean score before retirement ( $\mathrm{N}=1658)$. [95\% Cl= 95\% confidence interval.]

\begin{tabular}{|c|c|c|c|c|}
\hline & $\mathrm{N}$ & $\%$ & $\begin{array}{l}\text { Mean } \\
\text { score }\end{array}$ & $95 \% \mathrm{Cl}$ \\
\hline All & 1658 & 100 & 47.8 & $46.4-48.2$ \\
\hline \multicolumn{5}{|l|}{ Gender } \\
\hline Women & 1258 & 76 & 47.2 & $46.8-47.7$ \\
\hline Men & 400 & 24 & 49.6 & $48.9-50.4$ \\
\hline \multicolumn{5}{|c|}{$\begin{array}{l}\text { Characteristic before retirement } \\
\text { Number of chronic conditions }\end{array}$} \\
\hline 0 & 923 & 56 & 50.4 & $49.9-50.8$ \\
\hline 1 & 552 & 33 & 45.5 & $44.8-46.3$ \\
\hline$\geq 2$ & 183 & 11 & 41.8 & $40.6-43.2$ \\
\hline \multicolumn{5}{|l|}{ Obesity } \\
\hline No & 1335 & 81 & 48.7 & $48.3-49.1$ \\
\hline Yes & 323 & 19 & 44.2 & $43.1-45.2$ \\
\hline \multicolumn{5}{|c|}{ Physical activity } \\
\hline Active & 1251 & 75 & 48.6 & $48.1-49.1$ \\
\hline Inactive & 407 & 25 & 45.4 & $44.5-46.3$ \\
\hline \multicolumn{5}{|l|}{ Education } \\
\hline Basic & 383 & 23 & 46.1 & $45.3-47.1$ \\
\hline Intermediate & 756 & 46 & 47.4 & $46.8-48.0$ \\
\hline Higher & 519 & 31 & 49.7 & $49.0-50.3$ \\
\hline \multicolumn{5}{|c|}{$\begin{array}{l}\text { Physical working conditions be- } \\
\text { fore retirement }\end{array}$} \\
\hline \multicolumn{5}{|c|}{ Physical workload } \\
\hline 1 (Low) & 413 & 25 & 50.2 & $49.4-51.0$ \\
\hline 2 & 416 & 25 & 48.5 & $47.7-49.4$ \\
\hline 3 & 416 & 25 & 47.6 & $46.8-48.3$ \\
\hline 4 (High) & 413 & 25 & 45.0 & $44.1-45.8$ \\
\hline \multicolumn{5}{|c|}{ Environmental hazards } \\
\hline 1 & 413 & 25 & 50.5 & $49.8-51.1$ \\
\hline 2 & 416 & 25 & 48.9 & $48.1-49.6$ \\
\hline 3 & 416 & 25 & 47.3 & $46.4-48.1$ \\
\hline 4 & 413 & 25 & 44.7 & $43.8-45.6$ \\
\hline \multicolumn{5}{|c|}{ Computer work } \\
\hline 1 & 413 & 25 & 47.3 & $46.4-48.2$ \\
\hline 2 & 416 & 25 & 49.2 & $48.3-50.0$ \\
\hline 3 & 416 & 25 & 48.7 & $47.9-49.5$ \\
\hline 4 & 413 & 25 & 46.1 & $45.3-47.0$ \\
\hline
\end{tabular}

chronic diseases, obesity, physical activity and education attenuated the cross-sectional associations slightly, however, the main results did not change. The mutual adjustment for all three physical working conditions factors attenuated the cross-sectional associations, which remained significant in the highest workload categories (table 2). The adjustments had only minor effects on the mean changes of physical health functioning scores during the follow-up (table 3).

Both high and low exposure to computer work, were associated with lower physical health functioning before retirement (table 1). However, functioning among those in the lowest exposure quartile improved during the follow-up whereas functioning in all other exposure groups declined slightly (table 3 ), resulting into significantly lower post-retirement functioning among those in the highest as compared to the lowest exposure quartile (table 2). Further adjustments for obesity, chronic diseases and physical activity attenuated some of the associations, whereas the adverse associations between computer work and physical health functioning largely remained after adjustment for education and mutual adjustment for all of the three working conditions.

\section{Discussion}

Our results show that old-age retirees with higher exposure to adverse physical working conditions before retirement had lower pre- and post-retirement physical health functioning despite improvements in their functioning during the retirement transition process.

Our findings of the adverse effects of high physical workload on physical health functioning are in line with previous studies (5-8), but moreover, they extend the existing research by providing new evidence of the association between pre-retirement physical working conditions and changes in physical health functioning during retirement process, one of the major life transitions. Furthermore, previous studies have had a narrower focus examining the effect of physical workload only, overlooking the possible effects of other physical working conditions.

The observed impacts of environmental hazards on physical health functioning are also in line with the previous studies indicating that various environmental exposures are associated with many other adverse health outcomes. For example, high exposure to occupational noise, and to various irritating and hazardous substances have been associated with increased risk of coronary heart disease (12), cancer (14) and sickness absence (15), an important measure of global health (28). The correspondence with our results makes sense as functional limitations have also been associated with similar outcomes $(2,29,30)$.

Physical inactivity is known to have a deteriorating effect on physical functioning $(10,11)$. As occupational environment often limits employees' physical activity $(31,32)$, it has been suggested that sedentary work may also be associated with adverse health outcomes $(33,34)$. However, previous studies of the association between computer work and physical functioning are lacking. In our study, high exposure to sedentary computer work was associated with lower physical health functioning before and after retirement when adjusting for gender, age, obesity, chronic diseases and physical activity. Further adjustment for education changed the overall associations somewhat, indicating a close relationship between education and exposure to computer work.

Our previous study (8) showed that among ageing employees, exposure to adverse physical working conditions was associated with greater decline in physical health functioning over time. The present study among old-age retirees shows, in contrast, that those with high 
Table 2. Adjusted cross-sectional differences in Physical Component Summary (SF-36) mean scores by level of pre-retirement working conditions. [ref=reference; SE=standard error].

\begin{tabular}{|c|c|c|c|c|c|c|c|c|c|c|c|c|c|c|c|c|}
\hline \multirow{3}{*}{$\begin{array}{l}\text { Physical working } \\
\text { conditions } \\
\text { (quartiles 1-4) }\end{array}$} & \multicolumn{4}{|c|}{ Model $1^{a}$} & \multicolumn{4}{|c|}{ Model $2^{b}$} & \multicolumn{4}{|c|}{ Model $3^{c}$} & \multicolumn{4}{|c|}{ Model $4{ }^{d}$} \\
\hline & \multicolumn{2}{|c|}{$\begin{array}{c}\text { Before } \\
\text { retirement }\end{array}$} & \multicolumn{2}{|c|}{$\begin{array}{c}\text { After } \\
\text { retirement }\end{array}$} & \multicolumn{2}{|c|}{$\begin{array}{l}\text { Before } \\
\text { retirement }\end{array}$} & \multicolumn{2}{|c|}{$\begin{array}{c}\text { After } \\
\text { retirement }\end{array}$} & \multicolumn{2}{|c|}{$\begin{array}{l}\text { Before } \\
\text { retirement }\end{array}$} & \multicolumn{2}{|c|}{$\begin{array}{c}\text { After } \\
\text { retirement }\end{array}$} & \multicolumn{2}{|c|}{$\begin{array}{l}\text { Before } \\
\text { retirement }\end{array}$} & \multicolumn{2}{|c|}{$\begin{array}{c}\text { After } \\
\text { retirement }\end{array}$} \\
\hline & B & SE & $\beta$ & SE & B & SE & $B$ & SE & $\beta$ & SE & $\beta$ & SE & $\beta$ & SE & $\beta$ & SE \\
\hline \multicolumn{17}{|l|}{ Physical workload } \\
\hline 1 (Low) & ref. & & ref. & & ref. & & ref. & & ref. & & ref. & & ref. & & ref. & \\
\hline 2 & -1.7 & $0.6^{e}$ & -1.6 & $0.6^{e}$ & -1.2 & $0.5^{\mathrm{e}}$ & -1.3 & $0.5^{\mathrm{e}}$ & -1.6 & $0.6^{e}$ & -1.5 & $0.6^{e}$ & -1.0 & 0.6 & -1.1 & 0.6 \\
\hline 3 & -2.7 & $0.6^{\mathrm{e}}$ & -1.5 & $0.6^{\mathrm{e}}$ & -2.3 & $0.5^{\mathrm{e}}$ & -1.6 & $0.5^{\mathrm{e}}$ & -2.3 & $0.6^{\mathrm{e}}$ & -1.4 & $0.6^{\mathrm{e}}$ & -1.1 & 0.6 & -0.6 & 0.6 \\
\hline 4 (High) & -5.3 & $0.6^{\mathrm{e}}$ & -3.0 & $0.6^{e}$ & -4.3 & $0.5^{\mathrm{e}}$ & -2.0 & $0.5^{\mathrm{e}}$ & -4.6 & $0.6^{\mathrm{e}}$ & -2.8 & $0.6^{\mathrm{e}}$ & -2.8 & $0.7^{\mathrm{e}}$ & -1.9 & $0.7^{e}$ \\
\hline \multicolumn{17}{|c|}{ Environmental hazards } \\
\hline 1 (Low) & ref. & & ref. & & ref. & & ref. & & ref. & & ref. & & ref. & & ref. & \\
\hline 2 & -1.6 & $0.6^{\mathrm{e}}$ & -1.3 & $0.6^{\mathrm{e}}$ & -1.4 & $0.5^{\mathrm{e}}$ & -1.3 & $0.5^{\mathrm{e}}$ & -1.5 & $0.5^{\mathrm{e}}$ & -1.3 & $0.6^{\mathrm{e}}$ & 0.1 & 0.6 & 0.9 & 0.6 \\
\hline 3 & -3.2 & $0.6^{\mathrm{e}}$ & -2.2 & $0.6^{\mathrm{e}}$ & -2.5 & $0.5^{\mathrm{e}}$ & -1.5 & $0.5^{\mathrm{e}}$ & -2.9 & $0.6^{\mathrm{e}}$ & -2.0 & $0.6^{\mathrm{e}}$ & -0.7 & 0.6 & -0.5 & 0.6 \\
\hline 4 (High) & -5.8 & $0.6^{\mathrm{e}}$ & -2.8 & $0.6^{e}$ & -5.0 & $0.5^{\mathrm{e}}$ & -2.1 & $0.5^{\mathrm{e}}$ & -5.2 & $0.6^{\mathrm{e}}$ & -2.6 & $0.6^{\mathrm{e}}$ & -3.2 & $0.6^{\mathrm{e}}$ & -1.1 & 0.6 \\
\hline \multicolumn{17}{|l|}{ Computer work } \\
\hline 1 (Low) & ref. & & ref. & & ref. & & ref. & & ref. & & ref. & & ref. & & ref. & \\
\hline 2 & 1.9 & $0.6^{e}$ & 0.6 & 0.6 & 1.8 & $0.5^{\mathrm{e}}$ & 0.8 & 0.5 & 0.6 & 0.6 & -0.0 & 0.6 & 1.1 & 0.6 & 0.4 & 0.6 \\
\hline 3 & 1.4 & $0.6^{e}$ & -0.1 & 0.6 & 1.5 & $0.5^{\mathrm{e}}$ & 0.6 & 0.5 & -0.1 & 0.6 & -1.0 & 0.6 & -1.0 & 0.6 & -0.8 & 0.6 \\
\hline 4 (High) & -1.2 & $0.6^{e}$ & -2.6 & $0.6^{\mathrm{e}}$ & -0.9 & 0.5 & -1.9 & $0.5^{\mathrm{e}}$ & -2.7 & $0.6^{e}$ & -3.5 & $0.6^{e}$ & -3.0 & $0.6^{\mathrm{e}}$ & -3.4 & $0.6^{\mathrm{e}}$ \\
\hline
\end{tabular}

adjusted for gender and age.

${ }^{b}$ Adjusted for Model $1+$ Obesity, chronic diseases and physical activity.

${ }^{c}$ Adjusted for Model $1+$ Education.

${ }^{\text {a } A d j u s t e d ~ f o r ~ M o d e l ~} 1$ + All physical working condition factors adjusted simultaneously.

e Significantly $(P<0.05)$ different from the reference group.

Table 3. Adjusted mean change ( $B$ coefficients) of Physical Component Summary (SF-36) from before to after retirement by physical working condition quartiles before retirement. [SE=Standard Error]

\begin{tabular}{|c|c|c|c|c|c|c|c|c|}
\hline & \multicolumn{2}{|c|}{ Model 1 ${ }^{\mathrm{a}}$} & \multicolumn{2}{|c|}{ Model $2^{b}$} & \multicolumn{2}{|c|}{ Model $3^{c}$} & \multicolumn{2}{|c|}{ Model 4d } \\
\hline & B & SE & B & $\mathrm{SE}$ & B & SE & B & $\mathrm{SE}$ \\
\hline \multicolumn{9}{|c|}{ Physical workload } \\
\hline 1 (Low) & -0.8 & $0.4 \mathrm{e}, \mathrm{f}$ & -0.2 & $0.4^{f}$ & -0.8 & 0.4 e.f & -0.8 & $0.4^{e, f}$ \\
\hline 3 & 0.4 & $0.4^{\mathrm{f}, \mathrm{g}, \mathrm{h}}$ & 0.6 & $0.4^{f}$ & 0.4 & $0.4^{\mathrm{f}, \mathrm{g}, \mathrm{h}}$ & 0.4 & $0.4^{\mathrm{f}, \mathrm{g}, \mathrm{h}}$ \\
\hline 4 (High) & 1.5 & $0.4 \mathrm{e}, \mathrm{g}, \mathrm{h}$ & 2.1 & $0.4 \mathrm{e}, \mathrm{g}, \mathrm{h}$ & 1.5 & $0.4 \mathrm{e}, \mathrm{g}, \mathrm{h}$ & 1.5 & $0.4^{e, g, h}$ \\
\hline \multicolumn{9}{|c|}{ Environmental hazards } \\
\hline 1 (Low) & -1.1 & $0.4 \mathrm{e}, \mathrm{f}$ & -0.5 & $0.4^{f}$ & -1.1 & $0.4^{e, f}$ & -1.0 & $0.4^{e, f}$ \\
\hline 2 & -0.7 & $0.4^{f}$ & -0.4 & $0.4^{f}$ & -0.7 & $0.4^{f}$ & -0.7 & $0.4^{f}$ \\
\hline 3 & 0.1 & $0.4^{\mathrm{f}, \mathrm{g}}$ & 0.6 & $0.4^{f}$ & 0.1 & $0.4^{\mathrm{f}, \mathrm{g}}$ & 0.1 & $0.4^{\mathrm{f}, \mathrm{g}}$ \\
\hline 4 (High) & 2.0 & $0.4^{\mathrm{e}, \mathrm{g}, \mathrm{h}}$ & 2.4 & $0.4^{e, g, h}$ & 2.0 & $0.4^{e, g, h}$ & 2.1 & $0.4^{e, g, h}$ \\
\hline \multicolumn{9}{|c|}{ Computer work } \\
\hline 1 (Low) & 1.1 & 0.4 eff,h & 1.4 & $0.4^{f}$ & 1.1 & 0.4 e,th & 1.1 & 0.4 ef, h, \\
\hline 2 & -0.1 & $0.4 \mathrm{~g}$ & 0.2 & 0.4 & -0.1 & $0.4^{g}$ & -0.0 & $0.4^{g}$ \\
\hline 3 & -0.3 & $0.4 \mathrm{~g}$ & 0.3 & 0.4 & -0.3 & $0.4 \mathrm{~g}$ & -0.3 & $0.4 \mathrm{~g}$ \\
\hline 4 (High) & -0.4 & $0.4^{g}$ & 0.2 & $0.4^{g}$ & -0.4 & $0.4^{g}$ & -0.4 & $0.4^{g}$ \\
\hline
\end{tabular}

adjusted for gender and age.

${ }^{\mathrm{b}}$ Adjusted for Model $1+$ Obesity, chronic diseases and physical activity.

${ }^{\mathrm{c}}$ Adjusted for Model $1+$ Education.

${ }^{\mathrm{d}}$ Adjusted for Model $1+$ all physical working condition factors adjusted simultaneously.

e Significantly $(P<0.05)$ different from the third quartile.

${ }^{\mathrm{f}}$ Significantly $(P<0.05)$ different from the fourth quartile.

${ }^{9}$ Significantly $(P<0.05)$ different from the first quartile.

${ }^{\text {h }}$ Significantly $(\mathrm{P}<0.05)$ different from the second quartile.

pre-retirement exposure to physical workload or occupational environmental hazards, had improvements in their physical health functioning after retirement. It is likely that removal of these exposures after retirement reduces the related physiological load, which in turn can have a positive effect on physical health functioning and perceived physical capability (8). However, despite the observed improvements, the level of post-retirement functioning among those in the highest exposure groups remained lower than those in the lower exposure groups.

Low exposure to sedentary computer work was also associated with improvements in physical health functioning during the retirement transition process. Our additional analyses showed that a large proportion of 
those in the lowest computer work exposure category were in the highest physical workload (38\%) and environmental hazards ( $40 \%$ ) exposure categories (data not shown). Thus, as a substantial proportion of those with low exposure to computer work had a high exposure to physical workload and environmental hazards, the removal of these adverse occupational exposures after retirement transition may partly explain the observed improvements in physical health functioning among those with low exposure to computer work. It has been also suggested that retirement transition may be associated with beneficial changes in leisure time physical activity $(35,36)$, which in turn is known to improve physical functioning $(10,11)$. However, the evidence of the contribution of prior work-related physical load on physical activity during early retirement is inconclusive (37) and needs to be explored further in future studies.

We considered the contribution of obesity, chronic conditions, leisure time physical activity and education to the association between physical working conditions and physical health functioning. However, adjusting for these variables did not change the general conclusions, indicating that the deteriorating effects of adverse working conditions on physical health functioning were only partly dependent on these factors. When all of the three physical working condition factors were mutually adjusted, the pre-retirement differences in physical health functioning were highly comparable between the different working conditions: those with the highest exposures had around three points lower physical health functioning score than those with the lowest exposures (table 2). In post-retirement comparisons, the associations tended to be slightly stronger for computer work. Overall, these results indicate that high exposure to physical workload, environmental hazards and computer work all have important effects on physical health functioning among retiring employees. Future studies with more frequent follow-ups around the retirement transition process are needed to further investigate the most crucial occupational exposures. We also examined the effect of smoking, alcohol consumption, and marital status on the observed results, but they were not associated with the level or change in physical health functioning and had no impact on the observed associations. Therefore, they were omitted in the final analyses. Although previous studies have shown strong occupational class differences in the level and change of physical health functioning (29), we did not adjust the current analyses for occupational class due to potential risk of over adjustment.

Our study had several strengths. First, the longitudinal design allowed us to examine the association between pre-retirement physical working conditions and changes in physical health functioning during the retirement transition process. Second, the retirement data were derived from complete national registers, which makes our measure of old-age retirement valid and reliable. Third, we used the well-validated and widely used SF-36 PCS score to ascertain changes in physical health functioning during the prospective follow-up. Although the observed group differences in the means and mean changes of physical health functioning scores were fairly small, many of them were close to or greater than 3 points, which has been suggested as a clinically significant difference (39). Fourth, our measure of physical working conditions allowed us to examine the effect of diverse working conditions. Fifth, we used a large and well-characterized occupational cohort which included hundreds of different occupational titles.

This study had also limitations. When assessing the generalizability of the results, some characteristics of the data need to be considered. We studied an occupational cohort from the public sector with the majority of participants being women. However, the participation was broadly similar among women and men, although slightly more women than men responded to the surveys (23). Moreover, the gender distribution reflects that of the employees of City of Helsinki and largely the Finnish municipal sector in general. Furthermore, we restricted our analyses to those who retired due to old-age, whereas those who retired prematurely due to disability were excluded from the study. Further studies are needed to investigate how pre-retirement exposures to adverse physical working conditions affect physical health functioning among those who retire due to disability. Another limitation is that working conditions, physical health functioning and other health related factors were based on self-reported data and the possibility for under- or over-reporting cannot be ruled out. In addition, despite longitudinal study design, reverse causality cannot be totally ruled out, as those with poorer physical health functioning are likely to perceive more physical stress from various physical workloads compared to individuals with better physical health functioning. Furthermore, the measures of physical exposures were based solely on the presence of the demands in work and related level of discomfort, whereas frequency and duration were not assessed. Additionally, regression to the mean is a potential source of bias but it is unlikely to distort our results. Regression to the mean may cause only attenuation to the observed differences and, as a result, the true differences might be larger but not smaller than those observed in our study. Therefore, the results could be considered conservative. A further limitation is the reliance on two measurements of physical health functioning; one measurement before and one after retirement. The study would have benefitted from more frequent follow-ups to better detect changes in physical health functioning during the retirement transition process. 
In conclusion, the present findings showed that oldage retirees with a higher exposure to adverse physical working conditions before retirement had lower preand post-retirement physical health functioning despite improvements in their functioning during the retirement transition process.

\section{Acknowledgements}

This work was supported by the Finnish Work Environment Fund (grant 112231), the Academy of Finland (grants 1129225, 1257362) and the University of Helsinki. MM was supported by the Finnish Work Environment Fund (grant 115182) and the Juho Vainio Foundation. AK was supported by the Medical Research Council (MRC) (grant MR/K023241/1) and the Economic and Social Research Council (ESRC) (grant ES/L007509/1). TL was supported by the Academy of Finland (grant 287488).

\section{References}

1. Cooper R, Kuh D, Hardy R. Objectively measured physical capability levels and mortality: systematic review and metaanalysis. BMJ. 2010;341:c4467. http://dx.doi.org/10.1136/ bmj.c4467.

2. Cooper R, Kuh D, Cooper C, Gale CR, Lawlor DA, Matthews F, et al. Objective measures of physical capability and subsequent health: a systematic review. Age Ageing. 2011;40(1):14-23. http://dx.doi.org/10.1093/ageing/afq117.

3. Brown CJ, Flood KL. Mobility limitation in the older patient: a clinical review. JAMA. 2013;310(11):1168-77. http://dx.doi. org/10.1001/jama.2013.276566.

4. Stuck AE, Walthert JM, Nikolaus T, Bu CJ, Hohmann C, Beck JC. Risk factors for functional status decline in communityliving elderly people : a systematic literature review. Soc Sci Med. 1999;48(48):445-69. http://dx.doi.org/10.1016/S02779536(98)00370-0.

5. Geuskens GA, Burdorf A, Barendregt PJ, Hazes JM. A high physical workload and high job demands hamper the good prognosis in physical functioning in persons with early inflammatory joint conditions. Rheumatology. 2011;50:78998. http://dx.doi.org/10.1093/rheumatology/keq359.

6. Mänty M, Møller a, Nilsson C, Lund R, Christensen U, Avlund $\mathrm{K}$. Association of physical workload and leisure time physical activity with incident mobility limitations: a follow-up study. Occup Environ Med. 2014;71(8):543-8. http://dx.doi. org/10.1136/oemed-2013-101883.

7. Hinrichs T, von Bonsdorff MB, Törmäkangas T, von Bonsdorff ME, Kulmala J, Seitsamo J, et al. Inverse effects of midlife occupational and leisure time physical activity on mobility limitation in old age--a 28-year prospective follow-up study.
JAGS. 2014;62(5):812-20. http://dx.doi.org/10.1111/ jgs. 12793 .

8. Mänty M, Kouvonen A, Lallukka T, Lahti J, Lahelma E, Rahkonen O. Changes in working conditions and physical health functioning among midlife and ageing employees. Scand J Work Environ Health 2015;39(2):164-9. http://dx.doi. org/10.5271/sjweh.3521.

9. Gnudi S, Sitta E, Gnudi F, Pignotti E. Relationship of a lifelong physical workload with physical function and low back pain in retired women. Aging Clin Exp Res. 2009;21(1):55-61. http:// dx.doi.org/10.1007/BF03324899.

10. Stenholm S, Koster A, Valkeinen H, Patel K V., Bandinelli S, Guralnik JM, et al. Association of Physical Activity History With Physical Function and Mortality in Old Age. J Gerontol A Biol Sci Med Sci. 2016 Apr;71(4):496-501. http://dx.doi. org/10.1093/gerona/glv111 .

11. Cooper R, Mishra GD, Kuh D. Physical activity across adulthood and physical performance in midlife: findings from a British birth cohort. Am J Prev Med. 2011;41(4):376-84. http://dx.doi.org/10.1016/j.amepre.2011.06.035.

12. Koskinen H-L, Kauppinen T, Tenkanen L. Dual role of physical workload and occupational noise in the association of the metabolic syndrome with risk of coronary heart disease: findings from the Helsinki Heart Study. Occup Environ Med. 2011;68(9):666-73. http://dx.doi.org/10.1136/ oem.2010.057075.

13. Guo J, Kauppinen T, Kyyrönen P, Heikkilä P, Lindbohm ML, Pukkala E. Risk of esophageal, ovarian, testicular, kidney and bladder cancers and leukemia among Finnish workers exposed to diesel or gasoline engine exhaust. Int J Cancer. 2004;111(2):286-92. http://dx.doi.org/10.1002/ijc.20263.

14. Laakkonen a, Kyyrönen P, Kauppinen T, Pukkala EI. Occupational exposure to eight organic dusts and respiratory cancer among Finns. Occup Environ Med. 2006;63(11):72633. http://dx.doi.org/10.1136/oem.2005.025825.

15. Laaksonen M, Pitkäniemi J, Rahkonen O, Lahelma E Work arrangements, physical working conditions, and psychosocial working conditions as risk factors for sickness absence: Bayesian analysis of prospective data. Ann. Epidemiol. 2010;20(5):332-8. http://dx.doi.org/10.1016/j. annepidem.2010.02.004.

16. Westerlund H, Vahtera J, Ferrie JE, Singh-Manoux A, Pentti J, Melchior M, et al. Effect of retirement on major chronic conditions and fatigue: French GAZEL occupational cohort study. BMJ. 2010;341:c6149. http://dx.doi.org/10.1136/bmj.c6149.

17. Westerlund H, Kivimäki M, Singh-Manoux A, Melchior M, Ferrie J, Pentti J, et al. Self-rated health before and after retirement in France (GAZEL): a cohort study. Lancet. 2009;374:1889-96. http://dx.doi.org/10.1016/S01406736(09)61570-1.

18. Jokela M, Ferrie J, Gimeno D, Chandola T, Shipley MJ, Head J, et al. From Midlife to Early Old Age. Health Trajectories Associated With Retirement. Epidemiology. 2010;21:284-90. http://dx.doi.org/10.1097/EDE.0b013e3181d61f53. 
19. Stenholm S, Westerlund H, Salo P, Hyde M, Pentti J, Head J, et al. Age-related trajectories of physical functioning in work and retirement: the role of sociodemographic factors, lifestyle and disease. J Epidemiol Community Health 2014;68(6):503-9. http://dx.doi.org/10.1136/jech-2013-203555.

20. Mein G, Martikainen P, Hemingway H, Stansfeld S, Marmot $M$. Is retirement good or bad for mental and physical health functioning? Whitehall II longitudinal study of civil servants. Am J Public Health. 2003;57:46-9. http://dx.doi.org/10.1136/ jech.57.1.46.

21. Ekerdt DJ, Baden L, Bossé R, Dibbs E. The effect of retirement on physical health. Am J Public Health 1983;73(7):779-83. http://dx.doi.org/10.2105/AJPH.73.7.779.

22. Descatha A, Herquelot E, Carton M, Sabbath EL, Goldberg $\mathrm{M}$, Zins $\mathrm{M}$, et al. Is physically arduous work associated with limitations after retirement? Findings from the GAZEL cohort. Occup Environ Med. 2016 Mar;73(3):183-6. http://dx.doi. org/10.1136/oemed-2015-103130.

23. Lahelma E, Aittomäki A, Laaksonen M, Lallukka T, Martikainen P, Piha K, et al. Cohort Profile: The Helsinki Health Study. Int J Epidemiol. 2012;42(3):722-30. http:// dx.doi.org/10.1093/ije/dys039.

24. Laaksonen M, Aittomäki A, Lallukka T, Rahkonen O, Saastamoinen P, Silventoinen K, et al. Register-based study among employees showed small nonparticipation bias in health surveys and check-ups. J Clin Epidemiol. 2008;61(9):900-6. http://dx.doi.org/10.1016/j.jclinepi.2007.09.010.

25. Piirainen H, Hirvonen M, Elo A. The work and health interview study 2003. Finnish Institute of Occupational Health, Basic report, Helsinki, Finland; 2003.

26. Lahelma E, Laaksonen M, Lallukka T, Martikainen P, Pietiläinen $\mathrm{O}$, Saastamoinen $\mathrm{P}$, et al. Working conditions as risk factors for disability retirement: a longitudinal register linkage study. BMC Public Health. 2012;12(1):309. http:// dx.doi.org/10.1186/1471-2458-12-309.

27. Ware JE, Kosinski M, Keller SD. SF-36 Physical and Mental Component Summary Measures: A User's Manual. The Health Institute, New England Medical Center: Boston, MA; 1994.

28. Kivimäki M, Head J, Ferrie JE, Shipley MJ, Vahtera J, Marmot MG. Sickness absence as a global measure of health : evidence from mortality in the Whitehall II prospective cohort study. Br Med J. 2003;327(364):1-6. http://dx.doi.org/10.1136/ bmj.327.7411.364.

29. Cavalheri V, Tahirah F, Nonoyama M, Jenkins S, Hill K. Exercise training undertaken by people within 12 months of lung resection for non-small cell lung cancer. Cochrane Database Syst Rev. 2013;7(7):CD009955. http://dx.doi. org/10.1002/14651858.cd009955.pub2.
30. Laaksonen M, Kääriä S, Leino-Arjas P, Lahelma E. Different domains of health functioning as predictors of sickness absence - a prospective cohort study. Scand J Work Env Health. 2011;37(3):213-8. http://dx.doi.org/10.5271/ sjweh.3131.

31. Sjöström M, Oja P, Hagströmer M, Smith BJ, Bauman A. Health-enhancing physical activity across European Union countries: the Eurobarometer study. J. Public Health. 2006;14(5):291-300. http://dx.doi.org/10.1007/s10389-0060031-y.

32. van Uffelen JGZ, Wong J, Chau JY, van der Ploeg HP, Riphagen I, Gilson ND, et al. Occupational Sitting and Health Risks. Am J Prev Med. 2010;39(4):379-88. http://dx.doi. org/10.1016/j.amepre.2010.05.024.

33. Owen N, Healy GN, Matthews CE, Dunstan DW. Too Much Sitting: The Population-Health Science of Sedentary Behavior. Exerc Sport Sci Rev. 2010;38(3):105-13. http://dx.doi. org/10.1097/JES.0b013e3181e373a2.

34. Shrestha N, Ijaz S, Kukkonen-Harjula KT, Kumar S, Nwankwo CP. Workplace interventions for reducing sitting at work. Cochrane database Syst. Rev. 2015;1:CD010912. http:// dx.doi.org/10.1002/14651858.cd010912.pub2.

35. Lahti J, Laaksonen M, Lahelma E, Rahkonen O. Changes in leisure-time physical activity after transition to retirement: a follow-up study. Int J Behav Nutr Phys Act. 2011;8(1):36. http://dx.doi.org/10.1186/1479-5868-8-36.

36. Sjösten N, Kivimäki M, Singh-Manoux A, Ferrie J, Goldberg $\mathrm{M}$, Zins $\mathrm{M}$, et al. Change in physical activity and weight in relation to retirement: the French GAZEL Cohort Study. BMJ Open. 2012;2:e00522. http://dx.doi.org/10.1136/ bmjopen-2011-000522.

37. Van Dyck D, Cardon G, Deforche B, De Bourdeaudhuij I The Contribution of Former Work-Related Activity Levels to Predict Physical Activity and Sedentary Time during Early Retirement: Moderating Role of Educational Level and Physical Functioning. PLoS One. 2015;10(3):e0122522. http://dx.doi.org/10.1371/journal.pone.0122522.

38. Pietiläinen $\mathrm{O}$, Laaksonen $\mathrm{M}$, Pitkäniemi $\mathrm{J}$, Rahkonen $\mathrm{O}$, Lahelma E. Changes of occupational class differences in physical functioning: a panel study among employees (20002007). J Epidemiol Community Health. 2012;66(3):265-70. http://dx.doi.org/10.1136/jech.2010.110270.

39. Samsa G, Edelman D, Rothman M, Williams G, Lipscomb J, Matchar D. Determining clinically important differences in health status measures: a general approach with illustration to the Health Utilities Index Mark II. Pharmacoeconomics. 1999;15:141-55. http://dx.doi.org/10.2165/00019053199915020-00003.

Received for publication: 2 February 2016. 